\title{
A specimen of Rhamphorhynchus with soft tissue preservation, stomach contents and a putative coprolite
}

David Hone, Donald M. Henderson, Francois Therrien, Michael B Habib

Despite being known for nearly two centuries, new specimens of the derived nonpterodactyloid pterosaur Rhamphorhynchus continue to be discovered and to reveal new information about their anatomy and palaeobiology. Here we describe a specimen held in the collections of the Royal Tyrrell Museum of Palaeontology, Alberta, Canada that shows both preservation and impressions of soft tissues, and also preserves material interpreted as stomach contents of vertebrate remains and, uniquely, a putative coprolite. The specimen also preserves additional evidence for fibers in the uropatagium. 


\section{A specimen of Rhamphorhynchus with soft tissue preservation, stomach contents and a putative coprolite}

9 2. Royal Tyrrell Museum of Palaeontology, Drumheller, Alberta, Canada.

3. Keck School of Medicine, University of Southern California, Bishop Research Building, Room 403, 1333 San Pablo Street, Los Angeles, California 90089, U.S.A.

*Corresponding author: d.hone@qmul.ac.uk

*Hone, D.W.E. ${ }^{1}$, Henderson, D.M. ${ }^{2}$, Therrien, F. ${ }^{2}$, Habib, M.B. ${ }^{3}$

1. School of Biological and Chemical Sciences, Queen Mary University of London, London, UK.

\section{Abstract:} pterodactyloid pterosaur Rhamphorhynchus continue to be discovered and to reveal new information about their anatomy and palaeobiology. Here we describe a specimen held in the collections of the Royal Tyrrell Museum of Palaeontology, Alberta, Canada that shows both preservation and impressions of soft tissues, and also preserves material interpreted as stomach contents of vertebrate remains and, uniquely, a putative coprolite. The specimen also preserves additional evidence for fibers in the uropatagium. 
Keywords: Pterosauria, rhamphorhynchoid, Rhamphorhynchinae, palaeoecology

Introduction:

Rhamphorhynchus is a derived non-pterodactyloid pterosaur known primarily from the Late

Jurassic 'plattenkalk' beds of the Solnhofen region in southern Germany. It is one of the best

known and most well represented of pterosaurs and is known from over 100 specimens, many of

which are complete and articulated. This includes specimens preserved in three dimensions, and those that have extensive soft tissue preservation (see Wellnhofer, 1975; Frey et al., 2003; Hone et al., 2013). The derived Cretaceous pterodactyloid Pteranodon is a rival for this title, being known from many more specimens (in excess of 1000), many are only isolated elements or fragmentary remains, but soft tissues are unknown (Bennett, 2001). Certainly Rhamphorhynchus is the best known of the non-pterodactyloid pterosaurs, and as such presents a useful study model for many aspects of pterosaur research and has been central to many studies of various aspect of pterosaur biology (e.g. Bennett, 1995, 2007; Bonde \& Christiansen, 2003; Claessens et al., 2009; Henderson, 2010; Prondvai et al., 2012).

40 Pterosaur research is perhaps on the cusp of a revolution with a rapid growth in the number 41 of specimens recovered, research and understanding of the clade (Hone, 2012a). As a result, rarely preserved features such as wing membranes or stomach contents are vital to reconstructing the ecology and behavior of pterosaurs, even if they are present from otherwise well-studied taxa.

44 The diet of pterosaurs in particular is controversial and difficult to reconstruct (e.g. see 
45 Humphries et al., 2007; Tütken \& Hone, 2010; Ösi, 2012; Witton \& Niash, in press) and tropic

interactions are key to our understanding of the ecology and behavior of these animals. Despite a wealth of complete specimens, and the often exceptional nature of the preservation, direct evidence of trophic interactions based on stomach contents remains exceptionally rare for pterosaurs. Rhamphorhynchus has commonly been interpreted as being piscivorous based on the long, anteriorly directed and conical teeth, their presence in aquatic systems (Wellnhofer, 1975), and most convincingly, several specimens seen to have consumed fish (Wellnhofer, 1975; Unwin, 2005; Frey \& Tischlinger, 2012; Hone et al., 2013).

Despite a long history of research and discovery, new specimens of Rhamphorhynchus continue to be discovered with specimens heralding from ongoing excavations (e.g. Frey \& Tischlinger, 2012), specimens in collections that had not previously been described (e.g. Hone, 2012b) or those which have been residing in private collections before becoming available to researchers. Here we describe a new specimen of Rhamphorhynchus (TMP 2008.41.001 - Fig. 1) that was recently acquired by the Royal Tyrrell Museum of Palaeontology in Alberta, Canada. This preserves extensive impressions of soft tissues, stomach contents of a vertebrate, and a putative coprolite.

Institutional Abbreviations: BSP: Bayerische Staatssammlung für Paläontologie und Geologie, Munich, Germany; CM, Carnegie Museum of Natural History, Pittsburgh, Pennsylvania, U.S.A.; IVPP, Institute of Vertebrate Paleontology and Paleoanthropology, Beijing, China; NMINH, National Museum of Ireland, Natural 
History, Dublin, Ireland; PIN, Palaeontological Institute, Russian Academy of Sciences, Moscow, Russia; SMNK, Staatliches Museum für Naturkunde Karlsruhe, Karlsruhe, Germany; TMP: Royal Tyrrell Museum of Palaeontology, Drumheller, Canada; YPM: Yale Peabody Museum, New Haven, USA.

\section{Locality Information:}

Solnhofen, Schernfeld quarry, from Bavaria, Southern Germany.

\section{Systematic Palaeontology:}

Pterosauria

Rhamphorhynchidae

Rhamphorhynchus

R. muensteri
Kaup, 1834

Seeley, 1870

von Meyer, 1847

Goldfuss, 1831

Here we follow Bennett (1995) in considering all Solnhofen specimens of Rhamphorhynchus to belong to a single species, $R$. muensteri. The genus has previously been split into a dozen or more species but these have convincingly been shown to consist of juveniles and subadults of a single species (see Bennett, 1995 for a review). Bennett (1995) provided a strong diagnosis for $R$. muensteri with numerous autapomorphies, though several of the characters are also present in the recently named Bellubrunnus (Hone et al., 2012). TMP 
872008.41 .001 clearly belongs to Rhamphorhynchus as it possesses the following features defined

88 by Bennett (1995) not seen in Bellubrunnus (Hone et al., 2012): ten teeth in the upper jaw and

89 seven in the dentary, anterior teeth long and angled anteriorly and laterally, posterior teeth

90 shorter and more vertical, upper temporal fenestra rounded, femur shorter than humerus. Two

91 remaining characters used by Bennett (1995) to define the genus cannot be observed in the

92 specimen: lower temporal fenestra narrow and smaller than the upper, and fourth premaxillary

93 tooth larger and more lateral than other premaxillary teeth. The former cannot be observed owing

94 to the orientation of the skull, but given the size and shape of the upper temporal fenestra is

95 likely correct, and the latter may be the result of intraspecific variation or taphonomic distortion

96 or a temporary condition during tooth growth or replacement.

\section{Description:}

Specimen TMP 2008.41.001 was purchased from Pangea Fossils Ltd. and brought to the

Royal Tyrrell Museum in February of 2008. Notes in the TMP database for the specimen state

that it was originally discovered in the Schernfeld Quarry in 1965 and held in possession of the

family that owned quarries around the Eichstätt area. This is one of a number of quarries in the

Solnhofen basin to have yielded Rhamphorhynchus specimens, but these were not common in

Schernfeld, with only five having previously been recorded by Bennett (1995). Comparison of

TMP 2008.41.001 with measurements of material in Wellnhofer (1975) suggests that this is not 
108 all observations and measurements of this specimen should be new to the scientific literature.

109 Rhamphorhynchus is known from over 100 specimens and is thoroughly described and

110 illustrated in the literature (Wellnhofer, 1975, 1978). Therefore this description focuses on

111 details not commonly seen or preserved in other specimens of the genus.

112 The specimen (Fig. 1) is an animal approximately $990 \mathrm{~mm}$ in wingspan measured as the

113 total of the lengths of both humeri, radii, wing metacarpals and all wing phalanges. The bones

114 are of a rich, dark brown colour, though some form of glue or preservative has been added to

115 parts of the skeleton. The bone surface is generally well preserved, though some cortex is lost

116 and broken (e.g. left wing phalanges 2 and 3), and may be present in any counterplate that may

117 exist for the specimen, or were removed and / or destroyed during preparation. The matrix is a

118 very pale yellow-white colour, with occasionally flecks of darker sediment, and there are some

119 black dendrites around the bones and along cracks in the slab.

120 Overall the specimen is in very good condition, well-preserved and articulated with some

121 elements or parts of them preserved in three dimensions. The specimen is presented primarily in

122 ventral view as shown by the position of the sternum overlapping various elements and the lack

123 of visible neural spines and zygapophyses on the cervical and dorsal vertebrae. Some

124 disarticulation has occurred with the shoulder girdles and wings having moved slightly from

125 their natural positions and the ribs and gastralia having been somewhat scattered over the chest

126 of the specimen and part of the centre of the chest has much calcite crystal build up under the 127 preserved elements.

128 The specimen also preserves impressions of both brachiopatagia and a tail vane, and some 


\section{.}

traces of the uropatagium (these membranes may also contain some fossilized soft tissues - see below). The abdomen preserves gut contents of an indeterminate vertebrate and there is also a pair of masses of material posterior to the pelvis interpreted as a coprolite.

\section{Skull and Mandible:}

The skull is presented in left dorsolateral view and is partially preserved in three dimensions, though is also somewhat crushed and the left side appears a little distorted (Fig. 2). Some sutures in the skull can be tentatively identified but these are mostly not clear, either because they are being obliterated as a result of cranial fusion during ontogeny, or owing to crushing of elements. All fenestrae of the skull on the left side except the lower temporal fenestra are clearly visible. A fragment of bone is visible through the naris which likely represents a part of the palate. The orbit also contains a T-shaped piece of bone ventral to the partial and poorly preserved sclerotic ring, and this is mostly likely a separated ectopterygoid of the palate.

$$
\text { The left ramus of the mandible is seen in left lateral view and is articulated with the skull. }
$$

Twelve teeth are preserved in the upper jaw and ten in the mandible. In both cases one or two are apparently only very small (left upper jaw alveoli 8 and 9, left dentary alveoli 3 and 5) and may represent either incipient replacement teeth emerging, or are from the other side of the jaws and so only the tips are visible. This would explain the rather higher count here than is normal for Rhamphorhynchus (ten in the upper jaw and seven in the mandible - Bennett, 1995).

Axial Skeleton: 
Rhamphorhynchus is known to have a numerous axial elements show pneumaticity based on

151 major cavities in bones coupled with pneumatopores that pierce the cortex (Bonde \&

152 Christiansen, 2003). However here, as with many specimens of this genus, no external

153 pneumatopores are visible.

154 A ring of bone $5 \mathrm{~mm}$ in diameter, but only $2 \mathrm{~mm}$ in length is visible at the rear of the skull

155 which is interpreted as the separated atlas (Fig. 2). The axis is partially hidden behind the back of

156 the skull and is in left ventrolateral view such at the left lateral process of the neural arch is

157 visible. The rest of the cervical series is complete (six vertebrae) and articulated and seen in

158 ventral view, although the transition between the cervical and dorsal series is hard to identify.

159 The cervicals are approximately square in shape and the left cervical ribs can be seen in

160 articulation suggesting that the left side is marginally more exposed than the right as a result of

161 crushing.

162 The dorsal series is difficult to observe as this is partially covered by sternal elements, ribs,

163 and gastralia (Fig. 3). Approximately ten dorsals are preserved in an articulated series and are

164 seen in left ventrolateral view.

165 The sacrum is well preserved and consists of four vertebrae (Fig. 4). This is very slightly

166 displaced (clockwise in ventral view) relative to both the distal end of the dorsal series and the

167 proximal end of the caudal series. The sacral ribs are broad and fused to the ilium. The tail is

168 preserved in left ventrolateral view as shown by the presence of the transverse process being

169 obscured on the first two vertebrae and the asymmetric presentation of the elongate chevrons and

170 zygapophyses. The divisions between the vertebrae are difficult to distinguish along the majority 
171 of the length of the tail and parts are covered by the left pes, so a vertebral count is not possible.

172 Proximally, several of the elongate vertebrae have disarticulated somewhat and are not closely

173 appressed to the caudal centra. The last six preserved caudals are very small (typically around

$1740.5 \mathrm{~mm}$ in length, though the terminal caudal appears to be just $0.05 \mathrm{~mm}$ long) and collectively

175 are the same length as the last unreduced caudal (4 $\mathrm{mm}$ in total). These tiny terminal caudals are

176 simple and lack the zygapophyses and chevrons of the other the caudal vertebrae, and nor are

177 they bounded by these extensions of the preceding vertebrae.

178 Numerous dorsal ribs and gastralia are preserved on the specimen but a count is not possible

179 given that many elements overlap one another. Many are disarticulated however, and their exact

180 original associations and positions cannot be fully determined. In particular, a number of

181 gastralia are displaced anteriorly and lie below the base of the cervical series (Fig. 3). One sternal

$182 \mathrm{rib}$ is preserved adjacent to the anteriormost dorsals and the left margin of the sternum, and

183 shows the typical form of these elements (see Claessens et al., 2009), which are rarely preserved.

184 Several other sternal ribs are preserved alongside the dorsal vertebral column, and two or three

185 further ones are positioned posterior to the sternum but none of these are well preserved.

Pectoral girdle and forelimbs:

188 The sternum is preserved and close to a natural position, with the left hand margin partly overlapping the proximal dorsal centra. The entire right wing, including the right pectoral girdle, has moved as an articulated unit to a position where it lies close to the pelvis. A part of the left scapulacoracoid is preserved close to its natural position but is mostly hidden by the sternum. 
192 The right scapula and coracoid are seen in ?anterior view and appear to be nearly fully fused 193 together into a single unit, the visible anterior edge of which has suffered some damage. The 194 distal part of the coracoid is partially buried in the matrix and is underneath a large calcite crystal. Both wings are well preserved and are nearly completely articulated (Figs. 5, 6), although the wing phalanges have rotated along their long axes relative to the proximal parts and the right wing metacarpal has separated from the radius and ulna. Both humeri are preserved in medial view, though the right is partially concealed below the femur. The right radius and ulna are better preserved than the left, but the proximal and distal ends of the right are concealed beneath the right humerus and proximal wing phalanx. The left carpals are present and apparently fused into the proximal and distal syncarpal blocks seen in adult pterosaurs, but are poorly preserved and neither pteroid can be seen. In the right wing, the distal parts of metacarpals 1 and 2 are seen having separated slightly from the wing metacarpal and the other elements of the manus are all preserved. In the left wing, only the penultimate phalanx of digit three and all three unguals are 205 visible.

Both wing fingers are present and articulated, although each wing finger has rotated about its 207 long axis and lies $180^{\circ}$ out of the position relative to the proximal parts of their respective wings. In the right wing, the extensor tendon process is fully fused to wing phalanx 1 . Both the left and right fourth wing phalanges are moderately posteriorly curved as seen in many pterosaur specimens, including a number of examples of Rhamphorhynchus (Hone et al., 2013), and these

211 also terminate in a squared-off tip. In the right wing, the very tip of the fourth wing phalanx is 212 slightly broken, however, there is a clear impression of the tip and this, like the left, is clearly 
213 blunt.

214

215 Pelvic girdle and hindlimbs:

216 The pelvis is partially disarticulated and some elements appear to have been lost. Both ilia

217 are articulated with the sacrum and appear to be fused to it. The anterior wings of the ilia are well

218 preserved, though the posterior wings are damaged and poorly preserved. The proximal part of

219 the right pubis is articulated with the right ilium, but only the articular end is visible and the rest

220 appears to be hidden below other elements. Only one ischium (?right) can be identified and this

221 is not articulated with, or fused to, the ilium or pubis, but instead has moved anteriorly and lies

222 close to the sternum. The left pubis cannot be seen and appears to be the only major element lost

223 from the specimen. Both prepubes are preserved but are in poor condition and covered by other

224 elements. They are in close association but are not articulated with one another and lie posterior

225 and ventral to the sacrum.

226 Both hindlimbs are complete and articulated though the right foot is partially hidden under

227 the right wing and the last phalanges of the left foot are hidden by the tail. The midshaft of the

228 right femur is also partially concealed by the right humerus, but the outline of the bone is visible.

230 Soft-tissues:

231 A number of soft tissues or their impressions are preserved in the specimen but in places it is

232 difficult to separate between the two possibilities. These are either impressed into the matrix or

233 raised above it, suggesting they are genuine features and not carved into the matrix artificially, or 
234 are the remnants of preparation marks etc. Both brachiopatagia are present (Figs. 5, 6) and in a 235 relatively natural position (i.e. have not dissociated and moved as seen in some pterosaur 236 specimens cf. Elgin et al., 2011) and are preserved as very faint transparent outlines on the 237 matrix. Each wing has a more narrow chord along most of its length than seen in some 238 specimens of Rhamphorhynchus (e.g. BSPG 1938 I 503a, the 'Dark Wing' specimen - Frey et al., 239 2003) suggesting some postmortem shrinkage of the membranes (Elgin et al., 2011). Both 240 brachiopatagia also appear to have a near $90^{\circ}$ turn in them level with the distal end of the radius 241 and ulna, and then become narrower towards the elbow and body. This is likely because the 242 medial part of the wing (the tenopatagium) has fewer or no actinofibrils compared to the more 243 distal part (the actinopatagium) and thus has less support and a greater tendency to shrink or 244 decay after death. Proximal to the elbow, the right tenopatagium (Fig. 6) is rather less clearly 245 preserved than the left actinopatagium (Fig. 5), but does appear to meet the left ankle as is 246 considered common, or even ubiquitous, for pterosaur wing membranes (Elgin et al., 2011).

247 Under low angle lighting, both actinopatagia show evidence of actinofibrils, though these 248 are considered most likely to be impressions of the fibers, rather than actual preserved soft 249 tissues, since the preserved wings are all but identical in colour to the underlying matrix and are 250 not carbonized or darker than the matrix as in most Solnhofen pterosaurs that preserve soft 251 tissues of the wing (e.g. BSPG 1938 I 503a, the 'Dark Wing' specimen, YPM 1778), and are 252 more similar to other specimens considered to be preserved as impressions (e.g. BSPG 1880 II 8). 253 
255 of their preservation, and this is compounded by the fact that the wing membranes have shrunk 256 from their original form. In addition, there must also be some folding to the membrane given the 257 rotation of the wing fingers and the fact that the distal membrane can be seen on both the leading and trailing sides of the right wingtip. Furthermore, at least some parts of the wings have been covered with some form of transparent preservative and brush marks (e.g. swirls) are clearly visible in places on the matrix. Some actinofibrils are visible on the distal left wing and lie subparallel to one another and the fourth wing phalanx as seen in other pterosaurs, including

Rhamphorhynchus (Bennett, 2000; Frey et al., 2003). The number and density of the actinofibrils

cannot be determined as they are too few and too poorly preserved (perhaps because they are impressions). Lying at approximately $45^{\circ}$ to the fibrils in the right wingtip are a series of short apparent grooves (these are approximately $0.3 \mathrm{~mm}$ in diameter and $1 \mathrm{~mm}$ in length) which are interpreted as small folds or wrinkles in the membrane because these are considerably larger than the typical diameter of actinofibrils in this genus (0.05 mm - Bennett, 2000).

The tips of the wing membranes appear to meet the distal ends of the fourth wing phalanx at an acute angle, and do not show the anteroposteriorly enlarged tips to the membranes as in other pterosaurs (including BSPG 1880 II 8). This may be as a result of postmortem shrinkage, or in the case of the right wing, a result of the folding of the membrane in conjunction with the rotation of the wing finger. The right wing membrane appears on both sides of the fourth phalanx as a result of the rotation of the wing along its long axis.

No part of the propatagium from either arm can be seen, but this is perhaps not surprising given that the pteroids are hidden or lost, and the way the arms have folded might also conceal 
276

277

these membranes even if preserved. Despite the poor preservation around the posterior part of the sacrum and the overlapping elements of the tail and pes, part of the uropatagium, or an impression of it, is preserved (Fig. 7). In the crux of the left hindlimb there is a series of very fine parallel striations running anteroposteriorly and parallel to the tibia, that in gross form matches those seen in the actinopatagia. However, there are unlikely to be stray actinofibrils from the wings given that the wings overall are intact and the tenopatagium, which, although less well preserved than the actinopatagium, would have few or no actinofibrils (Bennett, 2000). Pycnofibers (body covering fibers, that may also be present on the wings - see Kellner et al., 2009) are also not preserved elsewhere on the specimen, and the fibers seen here in the uropatagium are generally too long, thin and straight to be pycnofibers (cf. Kellner et al., 2009).

There are also no stray fibers on other parts of the slab, further suggesting that these are genuine and part of the uropatagium.

As with the actinofibrils, the fibers in the uropatagium are considered to be preserved primarily as impressions in the matrix, rather than true soft tissue preservation (although this alternative is not ruled out). The clearest part of the uropatagium is perhaps part of the trailing edge because it lies at the very distal end of the tibia (Fig. 8), suggesting a termination close to the ankle as seen in other pterosaurs (e.g. Sordes PIN 2585/3, Pterodactylus, BSPG 1937. I.18). At the distal edge of the uropatagium, a high number of fibrils can be seen to be parallel to the tibia and are associated with a pale yellow stain on the matrix. The individual fibers are approximately $0.06-0.1 \mathrm{~mm}$ in diameter, and although their length is difficult to identify, one at least is around $3 \mathrm{~mm}$ in length. These are densely packed, with around 12 fibers per $\mathrm{mm}$ of 
297

298

299

300

301

302

303

304

306

307

308

309

310

311

312

313

314

315

316

317

membrane (Fig. 8).

Additional striations are visible on the lateral edges of the two tibiae and left metatarsals.

These might be scratch marks from preparation, but this seems unlikely as these are in places soft tissues might be expected (decayed uropatagium, proximal tenopatagium, foot webbing) and the marks are very fine and very closely packed and parallel which seems unlikely to be generated by a preparator. Nor do they appear in areas around the skull or anterior to the leading edges of the wing fingers where preparation might be similar to that around the hindlimbs, and nor do they match marks made during preparation of the midsection to reveal the gut contents (done by the TMP in April, 2013). Finally, some of the striations of the uropatagium track across the uneven surface of the matrix (where the yellow staining lies - Fig. 8) suggesting these are not preparation scratches, but impressions tracking the surface of the matrix, and they are not associated with the preservative on the wings noted above, so are not brush marks. These then are most likely fibers of some form but their origin is not clear. The uropatagium has become displaced relative to the bones even in some exceptionally preserved specimens (e.g. Sordes PIN 2585-33). This may be a continuation of the uropatagium but displaced and visible lateral to the tibia.

3 A diamond-shaped tail vane (or an impression) is also preserved as a near-transparent stain on the specimen, though the dorsal side is preserved as a slight impression, and the ventral side is slightly raised above the level of the matrix (Fig. 6). The vane in total is $61 \mathrm{~mm}$ long and has a maximum height of $39 \mathrm{~mm}$. The distal end of this corresponds almost exactly with the tip of the very last reduced caudal of the tail. Very faint impressions of fibers are seen in the tail vane but 
these are sparse and difficult to separate from the apparent preparation scratches on the surface of the matrix. The fibers are of similar diameter to the impressions of actinofibrils in the distal parts of the brachiopatagia, and are aligned dorsoventrally (i.e. perpendicular to the caudals) in the vane.

The keratinous sheathes of several unguals are also preserved on the specimen as dark orange stains. These are present on the unguals of the right manus and the ungual of digit 1 of the left foot. The claw of manual digit 3 also includes a 'claw spike' that is approximately $1.5 \mathrm{~mm}$ in length. This spike is a kind of very thin and needle-like extension of the very tip of an ungual. Such a feature is seen on a number of Mesozoic ornithodirans (e.g. the azhdarchid SMNK PAL 3830, and the dromaeosaurid dinosaur Microraptor, IVPP V 1335 - DWEH pes obs, respectively 2012,2010 ) and extends off the tip of the bony ungual and may form part of the ungual, or be an additional element. The lack of the presence of claw sheathes and the keratinous ramphotheca may be the result of loss during preparation.

Finally there are some orange stains around the body of the specimen, which may represent decayed or modified soft tissues. Similar orange soft tissue stains are seen in other Solnhofen Rhamphorhynchus specimens (e.g. CM 11429, NMINH F 10172) and this inference here is supported by the orange colouration of the preserved claw sheathes (goethite stains). There are however, some other orange stains on the matrix not directly associated with the bony parts of the animal, but whether these may represent decayed and drifted organic tissues of the pterosaur, other organic remains, or some geological artefact is not clear. 


\section{Ingested material:}

Gut contents consisting of indeterminate vertebrate elements are preserved in the thoracic cavity of the specimen (Fig. 3). These elements are bounded by the ribs and other thoracic parts of the skeleton (i.e. the bones of the pterosaur lie both above and below the elements in question) and they do not conform in size or shape to any of the elements of the Rhamphorhynchus (and apparently only the pteroids and one part of the pelvis are missing from the specimen). Given the overall articulated and well-preserved nature of the specimen it is unlikely these elements have somehow drifted into this position from outside of the animal and are therefore considered to have been consumed items. A number of these consumed elements are present in the thoracic region which are likely ingested remains of food (i.e. gut contents), but most of these are distorted and difficult to identify though their overall shape appears to be that of squat cylinders. Their exact identity cannot be determined as they are incomplete and partially covered by other elements, and much of the chest cavity has calcite crystal buildup.

A putative coprolite is also preserved in association with the specimen (Fig. 9). This lies almost immediately posterior to the sacrum and thus in a position likely close to the cloaca in life. This has split in two, but the terminal ends of the separated pieces are largely straight and they are of the same size and shape, suggesting a single mass that split along a weak point, rather than two separate pieces. The smaller part (that is closer to the pterosaur's pelvis) is poorly preserved and shows calcite crystals and is $11 \mathrm{~mm}$ long and $3 \mathrm{~mm}$ across. The second mass is $8 \mathrm{~mm}$ long and $4 \mathrm{~mm}$ across and consists of many tens of small and pale comma-shaped or spike-like elements (Fig. 10). These are typically around $0.2-0.3 \mathrm{~mm}$ in length, though larger ones are 0.45 
360

361 362 363

364 365

$\mathrm{mm}$. Some tiny ones are around $0.05 \mathrm{~mm}$, and are more simple in shape, but these may be partially concealed under other elements as they only appear in the greatest concentration of these pieces.

\section{Discussion:}

Based on the size of the animal and the fusion of various skeletal elements, the specimen TMP 2008.41.001 is considered close to adult status, though there is a mixture of immature and mature characteristics present. In terms of size, it is within the most common range of sizes of elements seen in specimens of Rhamphorhynchus, and these are typically immature (Bennett, 1995) with few adults being known. A number of fused elements show that this animal is not a young juvenile - the scapula is fused to the coracoid and the wing extensor tendon process is fully fused to wing phalanx 1 with an obliterated suture (Figs. 3, 5, 6). However, the sutures of the skull are still somewhat visible and have not been obliterated as in adults (Fig. 2) and similarly, although the ilium appears well fused to the sacrum, the apparent separation of the pubis and ischium suggest they were not fully fused to each other or the rest of the pelvis (Fig. 4). The bone texture (where well preserved) is smooth and unlike those of very young pterosaurs (Bennett, 1995). Of Bennett's (1995) year classes for Rhamphorhynchus, the shape of the cranium of TMP 2008.41.001 is intermediate between year class 3 and 4 (and is probably closer to 4), but the mandible matches class 3 well (Bennett, 1995 - his Fig 5). The shape of the tail vane, being a diamond rather than closer to a triangle (as seen in mature specimens), also suggests immaturity (Bennett, 1995, Fig. 6). Collectively then, the evidence suggests that this 
specimen was not a young juvenile, nor an adult, but the fusion and even obliteration of some

382 sutures in the skeleton, combined with the wingspan and shape of the cranium suggest that it was 383 close to osteological maturity.

384 The somewhat unusual disarticulation pattern of the specimen is also worthy of comment.

385 The right wing has moved posteriorly, but the ischium has moved anteriorly, as have some of the 386 gastralia. Also the right scapulocoracoid has moved with the right wing, but the left wing is in a 387 natural position, though this has (as a unit), slightly separated from the left scapulocoracoid (Fig.

388 1). This implies that there was no consistent current or effects of dissociation during decay. The 389 animal presumably came to rest on the substrate on its back, and as the material decayed or was 390 compressed under sediment, collapsed in part to the right, leading to the displacement of the 391 sternum, sacrum and prepubes and perhaps the right wing, and the position of the left leg. 392 Bloating of the carcass during decay may have occurred (Allison \& Briggs, 1991) and would 393 explain the anterior movement of the gastralia and the expulsion of the putative coprolite, 394 although the preservation of the wing membranes suggests that there was generally little decay 395 here.

Osteology:

The tiny distal caudal vertebrae indicate that most Rhamphorhynchus tails were incomplete, even when they appear to be complete, since the distalmost unreduced caudal may have a 400 rounded posterior face similar to the terminal caudals of many tetrapods. Wellnhofer (1991) had 401 illustrated these tiny vertebrae before, but these are rarely preserved (presumably in part because 
402

403

404

405

406

407

408

409

410

411

412

413

414

415

416

417

418

419

420

421

422

they are not bounded by the chevrons and zygapophyses) and this feature was overlooked by Lü and Hone (2012) on pterosaur tail lengths. However, as they here constitute less than $1.6 \%$ of the total length of the tail, this is unlikely to have any real effect on the data presented to date by Lü and Hone (2012). It does however suggest that similar 'additional' caudals may have been present in other pterosaurs but are not often preserved, or may be lost due to careless preparation.

Soft tissues:

Despite large numbers of complete and articulated pterosaurs preserved in KonservätLagerstätte-type deposits, soft tissues remain rare for pterosaurs, though increasing amounts of material are being discovered and described (Sullivan et al., 2014). The brachiopatagia are probably still the most commonly preserved parts, although some soft tissues that might expect to be commonly preserved are still rare. For example, claw sheathes were first reported for pterosaurs from the Solnhofen in 2003 (Frey et al., 2003) and beaks are also little known, even though they were presumably present on edentulous pterosaurs as well as being known for toothed forms including Pterodactylus and Rhamphorhynchus (Frey et al., 2003). Thus the information preserved here (as preserved tissue and / or impressions) are of importance and do provide corroboration of existing hypotheses.

The part of wing membranes preserved here (Figs. 5, 6) are most likely the remains of impressions in the matrix, but some soft tissues may be preserved. This is difficult to determine as the wings are seen primarily in ventral view and actinofibrils may be concentrated in the ventral part of the wing (Padian \& Rayner, 1993) and can be preserved as natural casts in some 
423 specimens. We suggest that these are primarily casts, with the stains representing traces of soft 424 tissues, but this cannot currently be confirmed. The limited extent of the fibers seen in the 425 brachiopatagium may be a result of poor preservation, or because most of the wing is preserved and the fibers are buried within it. Examination under UV light did not reveal any additional details that can be seen under normal natural and artificial lights (see Supplementary figures).

This does not rule out the presence of soft tissues and imply that the wing membranes are

preserved only as impressions as soft tissues do not always fluoresce under UV illumination.

Future work with additional lights and filters may therefore reveal additional details. Destructive and / or chemical analysis of the specimen was not considered appropriate given the quality of the material.

The actinofibrils that are seen in the brachiopatagia do conform to the size and shape previously described for these structures in Rhamphorhynchus (and some other pterosaurs) being approximately $0.05 \mathrm{~mm}$ in diameter (Padian \& Rayner, 1993; Bennett, 2000; Frey et al., 2003) and these conform most closely to the type A wing fibers as described by Kellner et al. (2009).

Confirmation of fibers being present in the uropatagium (Fig. 7) is more important. These

have been reported before for pterosaurs, being also present in the holotype of the anurognathid

Jeholopterus (Kellner et al., 2009) where fibers are seen to be both subparallel to the long axis of the body and also perpendicular to the tibia as seen here, and fibers of some kind were also suggested for the uropatagium of Eudimorphodon (Wild, 1994). Unwin and Bakhurina (1994) also noted that the scaphognathine Sordes had a large uropatagium replete with fibers, but the size, shape and orientation of these was not discussed. As described above, a series of sub- 
444 parallel fibers are present implying the presence of the uropatagium towards the ankles of the 445 animal and imply a typically broad rhamphorhychoid-type uropatagium (e.g. see Unwin, 2005).

446 These are subparallel to the long axis of the body and suggest that fibers did help support the 447 uropatagium in this taxon. Frey et al (2003) also noted the presence of fibers with the 448 uropatagium in the 'Dark Wing' specimen of Rhamphorhycnhus but these were described as 449 being 'bushy' and their position on the lateral face of the tibia / fibula suggest these were in fact pycnofibers associated with the body rather than actinofibril-like fibers in the uropatagium itself.

451 The claw sheathes seen here do seem to be genuinely preserved soft tissues given their clear colour and texture differences to the surrounding matrix. The sheathes are smaller than many described for pterosaurs (e.g. see Frey et al., 2003) as the apparent extent of the sheath extends little beyond the claw-spike of the ungual. However, this may be a result of incomplete

Rhamphorhynchus should be sought from additional specimens.

The diet of Rhamphorhynchus:

459 Stomach contents for pterosaurs are very rare, despite the prevalence of these taxa in areas 460 of exceptional preservation that often include soft tissues (e.g. Sullivan et al., 2014). Rhamphorhynchus is perhaps already the genus with the most data in this regard, with several specimens being shown to have elements of fish (Wellnhofer, 1975; Hone et al., 2013), or even an entire fish having been consumed (Wellnhofer, 1975; Unwin, 2005; Frey \& Tischlinger, 2012). There is little doubt then that, as commonly suggested in the literature (Wellnhofer, 1978, 
465

466

1991; Unwin, 2003; Padian, 2008; Witton, 2013), Rhamphorhynchus was at least occasionally piscivorous.

This interpretation is further supported by the fact that Rhamphorhynchus itself was the victim of attacks by fish (Frey \& Tischlinger, 2012) suggesting they were spending significant amount of time over water, and isotope data supports their collecting food from marine systems (Tütken \& Hone, 2010), despite likely limitations when at rest on the surface of the water (Hone \& Henderson, 2014). The cranial morphology of Rhamphorhynchus and indeed other rhamphorhynchines does appear well suited to taking food from the water with numerous, anteriorly directed teeth and elongate jaws which extend further with a keratinous beak (Frey et al., 2003) as is seen on some modern piscivorous fish and contemperaneous marine predators including a number of plesiosaurs.

Although fish were clearly part of the diet, and Rhamphorhynchus was apparently specialised for taking aquatic prey, this would not rule out other sources of food. Unidentified remains in the stomach of a specimen of Rhamphorhynchus shows that diet was not exclusively fish (Wellhofer, 1991 p 160). Carnivorous animals will take animalian food items from well outside their 'typical' range if the food is available and there is no reason to think pterosaurs would be different. The specimen here preserves two different traces that in part suggest this genus may have had a diet beyond fish.

First, there are gut contents in the chest cavity of the specimen that are represented by indeterminate vertebrate elements. These bones may represent fish or tetrapod elements, but are not part of the pterosaur as they match none of the dissociated or missing material (ribs, gastralia, 
sternal ribs, pteroids, pelvic elements) but instead are a subrectangular series and associated subcircular elements that collectively may be vertebrae (Fig. 3). Possible identifications are the opercula of a sizeable fish, or small vertebrae from sharks, though in the case of the former these would be in the absence of all other elements, and the latter implies a more sizeable animal that a small pterosaur may have been able to tackle. Although we cannot absolutely verify the identity of these elements, it is possible that they are tetrapodan - for example in addition to the possibility they represent tetrapodan centra, they also bear a resemblance to some carpals and tarsals of marine crocodilians from the Solnhofen (e.g. Geosaurus). If so, this is the first case of consumption of tetrapodan food items by a pterosaur. Small tetrapods (both aquatic and terrestrial) are known from the Solnhofen (Barthel et al., 1990) and of course these would produce still smaller juvenile animals, which would form potential consumed items.

The calcite crystal mass underlying the stomach contents, suggests some hard organic matter was originally present because calcite crystals are commonly associated with cartilage in Solnhofen pterosaurs at least (Bennett, 2007). Thus while the only clearly identified remains are the putative vertebrae, the other elements and the calcite mass suggest a sizeable meal was originally present in the digestive tract of the pterosaur.

The part of the inferred coprolite closest to the pelvis of the animal (Fig. 9) is similarly indistinct and apparently consists of a calcite crystal mass again suggesting the presence of harder organic tissues as with the stomach contents. The second part is composed of tiny elements that are simple spikes and hook-like shapes (Fig. 10). These we originally suggested were hooklets from the arms or tentacles of a cephalopod (Hone et al., 2012) but we now 
tentatively reject this hypothesis as the morphology of the cephalopod hooks are a less good match than we had originally thought. A number of alternatives have also been assessed including the branchial apparatus of a small fish, and possible invertebrate origins such as spines from a small echinoderm or sponge spicules, but none are confident referrals. Examination of the remains of various vertebrates and invertebrates from the Solnhofen (e.g. the teleost fish Gyronchus, the sphenodontid Homeosaurus, the crocodyliform Geosaurus, an indeterminate echinoid and an indeterminate cephalopod - all DWEH pers obs, 2014) do not reveal any compelling matches, but this may be as a result of the unusual preservational situation.

These elements have passed through the digestive tract of an animal and thus will have been affected by digestive processes. They have then been deposited alongside various chemicals and in a fecal mass which would make for a very different local condition to specimens normally preserved in the Solnhofen. Either of these two issues, or both in combination, may have affected the preservational potential of the 'hooks' or their appearance and thus identifying them may prove very difficult.

If the diagnosis is correct, this is the first recorded coprolite for any pterosaur. Coprolites are rare for many vertebrate clades (Hunt et al., 2012), and it is likely Rhamphorhynchus defecated over water causing the breakup of the excreted matter. Preservation here is likely as a result of the material being expelled postmortem and in a low energy system thus preventing the dissipation of the fecal pellet. Data from the extant phylogenetic bracket for pterosaurs (crocodilians and birds) and from the digestion and excretion by Mesozoic non-avian dinosaurs is variable. Birds typically produce a near liquid mass, while crocodilians typically produce solid 
pellets, these can break down quickly (Fisher, 1981). However, a more solid coprolite is known for some birds, and at least one large Mesozoic theropod (Chin et al. 1998). The preservation here of even tiny elements suggests a relatively low amount of acid in the stomach because these have not been destroyed or damaged by their passage (cf Fisher, 1981; Andrews \& FernandezJalvo, 1998 on crocodilian digestion and waste).

Although we no longer consider the putative coprolite evidence of direct feeding on cephalopods by pterosaurs, this is a plausible hypothesis and worthy of further consideration.

Cuttlefish and especially squid match the general form of fish and prey capture would be similar

for both, as demonstrated in many modern birds and large predatory fish that may take fish or squid, in addition to some fossil taxa. A diet including both fish and cephalopods has been shown in Larus (gull) species (Baltz \& Morejohn, 1977), in pelagic sharks (Lowe et al., 1996) and marine ichthyosaurs (Pollard, 1968). Although some authors may have considered the idea of cephalopods as part of the pterosaur diet implicit in the term 'piscivory' it does not seem to have been explicit, even in cases where cephalopods are mentioned. For example, Kemp (2001) noted that both fish and cephalopods would have been in the upper waters of the Solnhofen and local crocodilians would have fed there on both, but despite suggesting pterosaurs would also be limited to feeding in this zone, he suggested they were piscivorous. explicit the possible prey range encompassed. Both data and analyses of pterosaur diets are increasing (Humphries et al., 2007; Tütken \& Hone, 2010; Ösi, 2011; Witton \& Naish, in press) but understanding will be hindered with ambiguous terminology. Even so, the new information 
549 here does tentatively suggest a broader diet for pterosaurs than simply fish, and the rapid increase

550 in study in this area is likely to shed additional light on the foraging and feeding behaviour of

551 pterosaurs.

552

\section{Acknowledgements:}

554 We thank Brandon Strilisky, Graeme Housego, and Rhian Russell for assistance with access to 555 material held at the Royal Tyrrell Museum. Dawna MacLeod is thanked for the preparation work

556 to further expose elements of the chest and the tip of the tail. Sue Sabrowski is thanked for the

557 UV photographs used in the supplementary files and we thanks Tom Courtenay and Martin

558 Schilling for assisting her. Jim Gardner is thanked for use of his microscope camera. Helmut

559 Tischlinger is thanked or information on the origins of the specimen and we also thank him,

560 Donald Brinkman, Alistair McGowan, David Martill, Lorna Steel, Kenneth De Baets, Andrew

561 Smith, Leititia Adler, Dirk Fuchs, Jakob Vinther, Matthias Mäuser and Andrew Newman for

562 discussions on the identity of the stomach contents and coprolite. Our thanks to Martin Roper for

563 allowing DWEH to access specimens at the Solnhofen Museum. We thank Kenneth De Baets for

564 this work as an editor and also Dino Frey and an anonymous referee for their comments that

565 helped improve the manuscript.

References: 
Allison PA, Briggs DEG. 1991. Taphonomy of non-mineralized tissues. In: Briggs DEG, Allison PA eds. Taphonomy: Releasing the data locked in the fossil record, Plenum Press, 26-70.

Andrews P, Fernandez-Jalvo Y. 1998. Palaeobiology: 101 uses for fossilized feces. Nature 393:629-630.

Baltz DM, Morejohn GV. 1977. Food habits and niche overlap of seabirds wintering on Monterey Bay, California. The Auk, 94:526-543.

Barthel KW, Swinburne NHM, Conway Morris S. 1990. Solnhofen: a study in Mesozoic paleontology. Cambridge University Press.

Bennett SC. 1995. A statistical study of Rhamphorhynchus from the Solnhofen Limestone of Germany: year-classes of a single large species. Journal of Paleontology 69:569-580.

Bennett SC. 2000. Pterosaur flight: the role of actinofibrils in wing function. Historical Biology $14: 255-284$.

Bennett SC. 2001. The osteology and functional morphology of the Late Cretaceous pterosaur Pteranodon. Palaeontographica A 260:1-153.

Bennett SC. 2007. A second specimen of the pterosaur Anurognathus ammoni. Paläontologische Zeitschrift, 81:376-398.

Bonde N, Christiansen P. 2003. The detailed anatomy of Rhamphorhynchus: axial pneumaticity and its implications. In: Buffetaut E, Mazin J-M eds. Evolution and Palaeobiology of Pterosaurs. Geological Society Special Publication 217, 217-232.

Chin K, Tokaryk TT, Erickson GM, Calk LC. 1998. A king-sized theropod coprolite. Nature 393:680-682. 
590 Claessens LPM, O’Connor PM, Unwin DM. 2009. Respiratory evolution facilitated the origin of $591 \quad$ flight and aerial gigantism. PLoS ONE 4:e4497.

592 Elgin RA, Hone DWE, Frey E. 2011. The extent of the pterosaur flight membrane. Acta 593 Palaeontologica Polonica, 56:99-111.

Fisher DC. 1981. Crocodilian scatology, microvertebrate concentrations, and enamel-less teeth. Paleobiology, 262-275.

Frey, E, Tischlinger, H. 2012. The Late Jurassic pterosaur Rhamphorhynchus, a frequent victim of the ganoid fish Aspidorhynchus? PLoS ONE, 7:e31945.

Frey E, Tischlinger H, Buchy M-C, Martill DM. 2003. New specimens of Pterosauria (Reptilia) with soft parts with implications for pterosaurian anatomy and locomotion. In: Buffetaut E, Mazin J-M eds. Evolution and Palaeobiology of Pterosaurs. Geological Society Special Publication 217, 233-266.

Goldfuss A. 1831. Beiträge zur Kenntnis verschiedener Reptilien der Vorwelt. Nova acta Academiae caesareae Leopoldino-Carolinae germanicae naturae curiosorum 15:61-128.

Henderson DM. 2010. Pterosaur body mass estimates from three-dimensional mathematical slicing. Journal of Vertebrate Paleontology 30:768-785.

Hone DWE. 2012a. Pterosaur research: recent advances and a future revolution. Acta Geologica Sinica 86:1366-1376.

Hone DWE. 2012b. A new specimen of the pterosaur Rhamphorhynchus. Historical Biology 24:581-585.

610 Hone DWE, Henderson DM. 2014. The posture of floating pterosaurs: ecological implications 
for inhabiting marine and freshwater habitats. Palaeogeography, Palaeoclimatology, Palaeoecology 398:89-98.

Hone DWE, Tischlinger H, Frey E, Röper M. 2012. A new non-pterodactyloid pterosaur from the Late Jurassic of Southern Germany. PLoS ONE 7:e39312.

Hone DWE, Habib MB, Lamanna MC. 2013. An annotated and illustrated catalogue of Solnhofen (Upper Jurassic, Germany) pterosaur specimens at Carnegie Museum of Natural History. Annals of Carnegie Museum 82:165-191. of Fishes, 47:203-211.

Humphries S, Bonser RHC, Witton MP, Martill DM. 2007. Did pterosaurs feed by skimming? Physical modelling and anatomical evaluation of an unusual feeding method. PLoS Biology 5:1647-1655.

Hunt AP, Lucas SG, Milàn J, Spielmann JA. 2012. Vertebrate coprolite studies: status and prospectus. New Mexico Museum of Natural History and Science Bulletin 57:5-2.

Kaup JJ. 1834. Versuch einer Eintheiling der Säugetiere. Isis von Oken, Jena 311-316.

Kellner AWA, Wang X, Tischlinger H, Campos DA, Hone DWE, Meng X. 2009. The soft tissue of Jeholopterus (Pterosauria, Anurognathidae, Batrachognathidae) and the structure of the pterosaur wing membrane. Proceedings of the Royal Society, Series B 277:321-329.

Kemp, R. 2001. Generation of the Solnhofen tetrapod accumulation. Archaeopteryx 19:11-28.

Lowe CG, Wetherbee BM, Crow GL, Tester AL. 1996. Ontogenetic dietary shifts and feeding behavior of the tiger shark, Galeocerdo cuvier, in Hawaiian waters. Environmental Biology 
pterosaurian tail lengths. Acta Geologica Sinica 86:1317-1325.

633

634

635

636

637

638

Meyer CEHv. 1847. Homeosaurus maximiliani und Rhamphorhynchus (Pterodactylus) longicaudus, zwei fossile aus der Kalkschiefer von Solnhofen, Frankfurt.

Ösi A. 2011. Feeding-related characters in basal pterosaurs: implications for jaw mechanism, dental function and diet. Lethaia 44:136-152.

Padian K. 2008. The Early Jurassic Pterosaur Dorygnathus banthensis (Theodori, 1830). Special Papers of the Palaeontological Association 80:1-61.

Padian K, Rayner JMV. 1993. The wings of pterosaurs. American Journal of Science 293-A:91166.

Persons WS, Currie PJ. 2012. Dragon tails: convergent caudal morphology in winged archosaurs. Acta Geologica Sinica (English edition) 86:1402-1412.

Pollard JE. 1968. The gastric contents of an ichthyosaur from the Lower Lias of Lyme Regis, Dorset. Palaeontology, 11:376-388.

Prondvai E, Stein K, Ösi A, Sander MP. 2012. Life history of Rhamphorhynchus inferred from bone histology and the diversity of pterosaur growth strategies. PLoS ONE 7:e31392.

Schweigert G. 2007. Ammonite biostratigraphy as a tool for dating upper Jurassic lithographic limestones from South Germany - first results and open questions. Neues Jahrbuch für Geologie und Paläontologie 1:117-125.

Seeley HG. 1870. The Ornithosauria: an elementary study of the bones of pterodactyles. Deighton, Bell, and Co., Cambridge.

Sullivan C, Wang Y, Hone DWE, Wang YQ, Xu X, Zhang F. 2014. The vertebrates of the 

$34: 243-280$.

Tütken T, Hone DWE. 2010. The ecology of pterosaurs based on carbon and oxygen isotope analysis. Acta Geoscientica Sinica 31:65-67. Publication 217, 139-190.

Unwin DM. 2005. The Pterosaurs from Deep Time. Pi Press, New York.

Unwin DM, Bakhurina NN. 1994. Sordes pilosus and the nature of the pterosaur flight apparatus.

Wild R. 1994. A juvenile specimen of Eudimorphodon ranzii Zambelli (Reptilia, Pterosauria) from the Upper Triassic (Norian) of Bergamo. Rivista del Museo civico di Scienze Naturali "Enrico Caffi", Bergamo 16: 95-120.

Wellnhofer P. 1975. Die Rhamphorhynchoidea (Pterosauria) der Oberjura-Plattenkalke 667 Süddeutschlands. Palaeontographica Abteilung A 148:1-33; 132-186; 149:1-30. Stuttgart. $82 \mathrm{pp}$.

Wellnhofer P.1991. The Illustrated Encyclopedia of Pterosaurs. London: Salamander Books.

Witton MP. 2013. Pterosaurs: Natural History, Evolution, Anatomy. Princeton University Press.

Witton MP, Naish D. In press, Azhdarchid pterosaurs: water-trawling pelican mimics or "terrestrial stalkers"? Acta Palaeontologica Polonica. 
1

Figure 1

Figure 1: Specimen TMP 2008.41.001 of Rhamphorhynchus muensteri. Scale bar is $100 \mathrm{~mm}$.

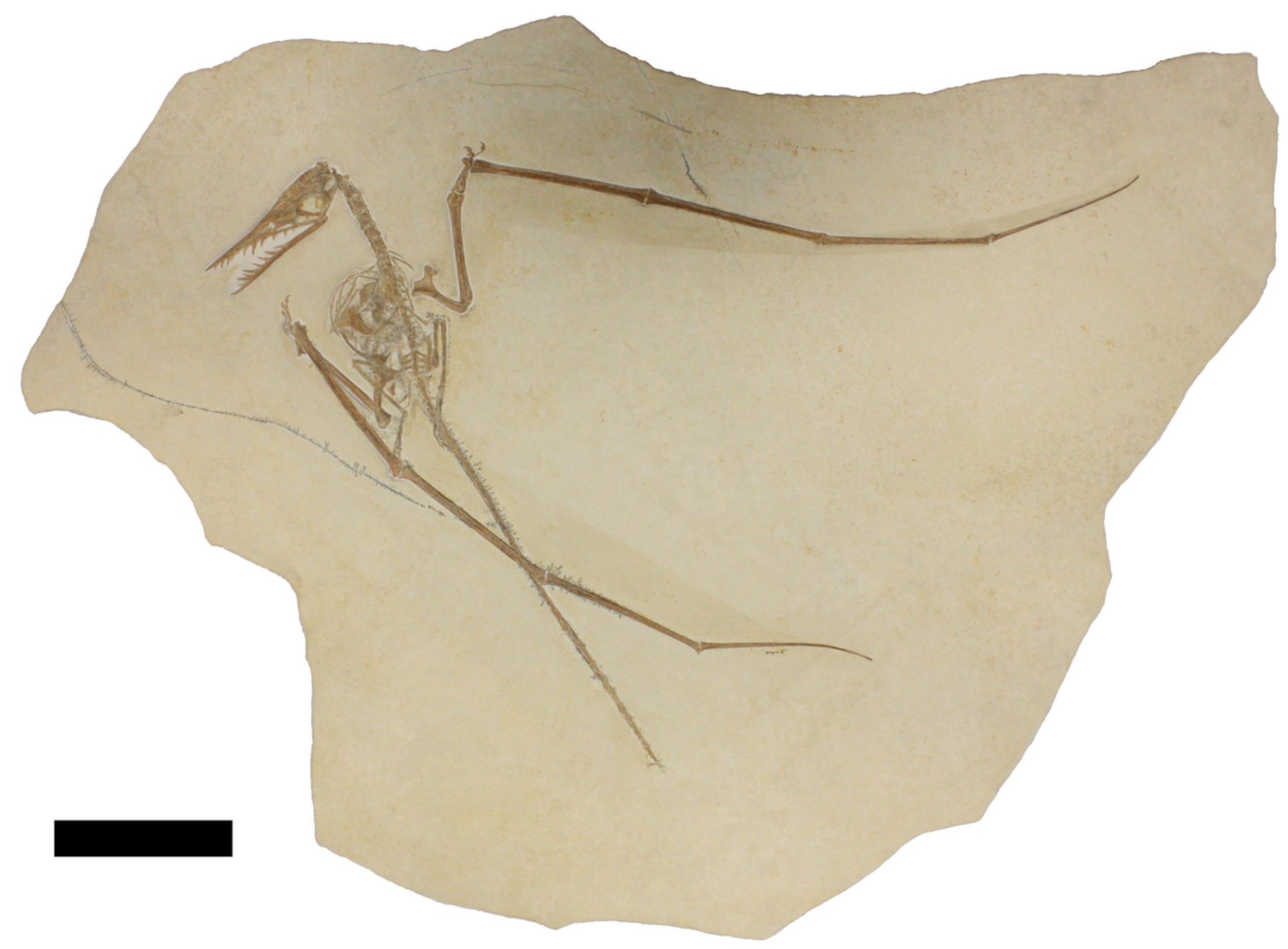




\section{2}

Figure 2

Figure 2: Photograph of skull showing the ring-like atlas at the rear of the skull and palatal element sitting inside the ventral part of the orbit. Scale bar is $50 \mathrm{~mm}$.

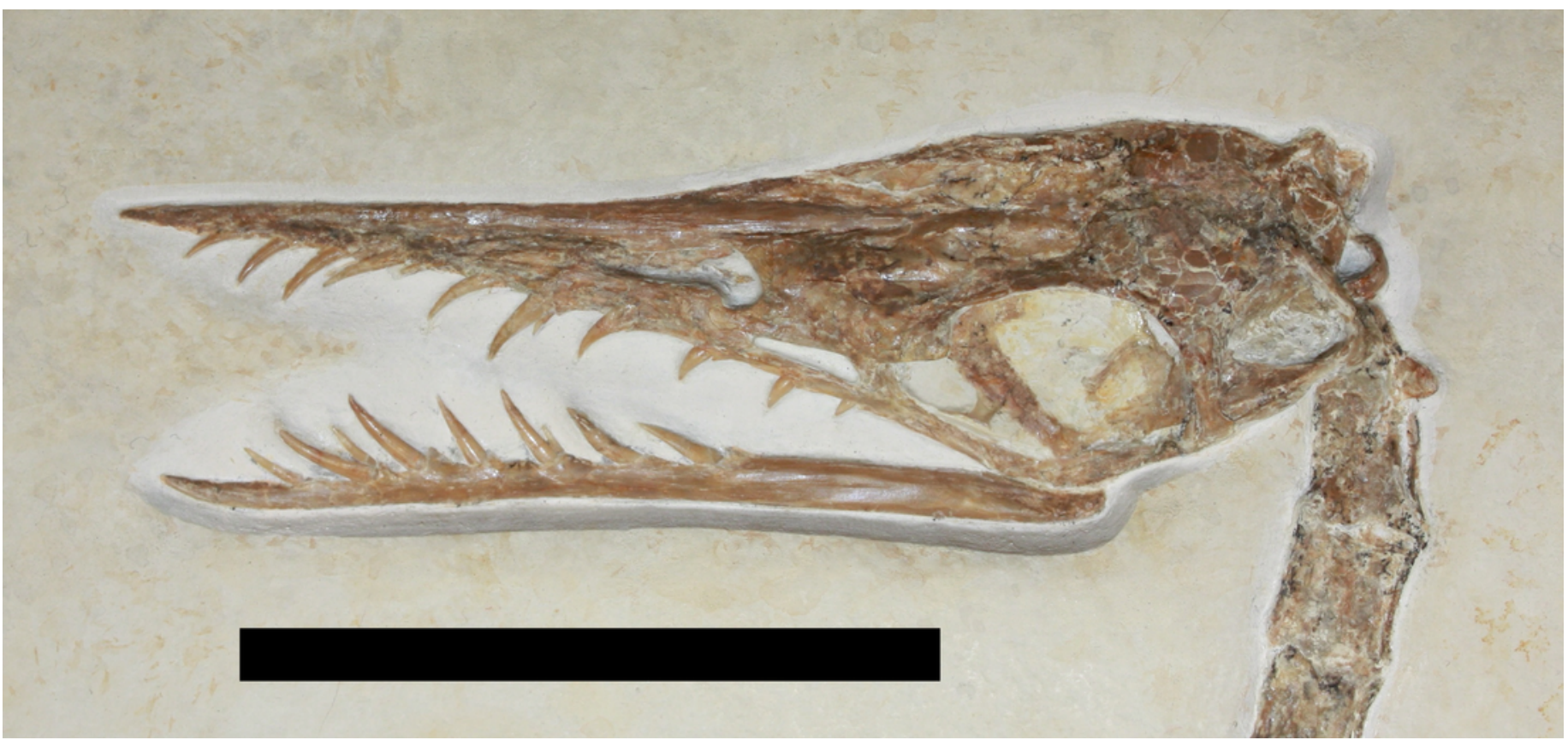




\section{3}

Figure 3

A: Close-up of chest cavity and inferred gut contents in the abdominal region. Scale bar is 20 $\mathrm{mm}$. B: Map of the major elements seen in figure 3. Bony elements are in dark grey and abbreviations are as follows: cdv, caudal vertebrae; cv, cervical vertebrae; dr, dorsal rib; dv, dorsal vertebrae; fe, femur; hu, humerus; il, ilium; ish, ischium; mc, metacarpal; r, ribs; sc, scapulocoracoid; sac, sacrum; st, sternum; ti, tibia. Possible stomach contents are in light grey - note that the preservation in this area is poor and parts of the highlighted region consist primary of calcite. Key areas are the possible vertebrae ( $v$ ) and the long, thin bony rods (br).

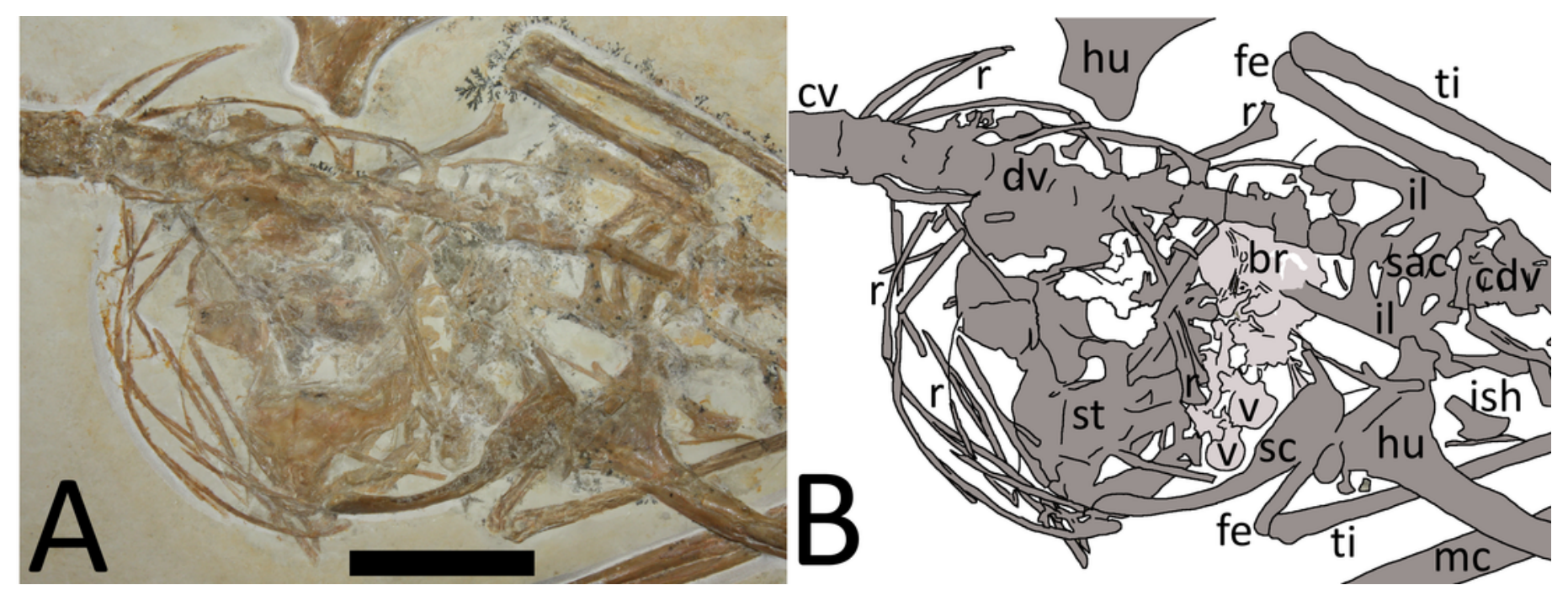


4

Figure 4.

Figure 4: Close-up of hindlimbs and associated region. Abbreviations as per figure 3 , with the following additions: $\mathrm{cp}$, coprolite; ps, pes. Scale bar is $10 \mathrm{~mm}$.

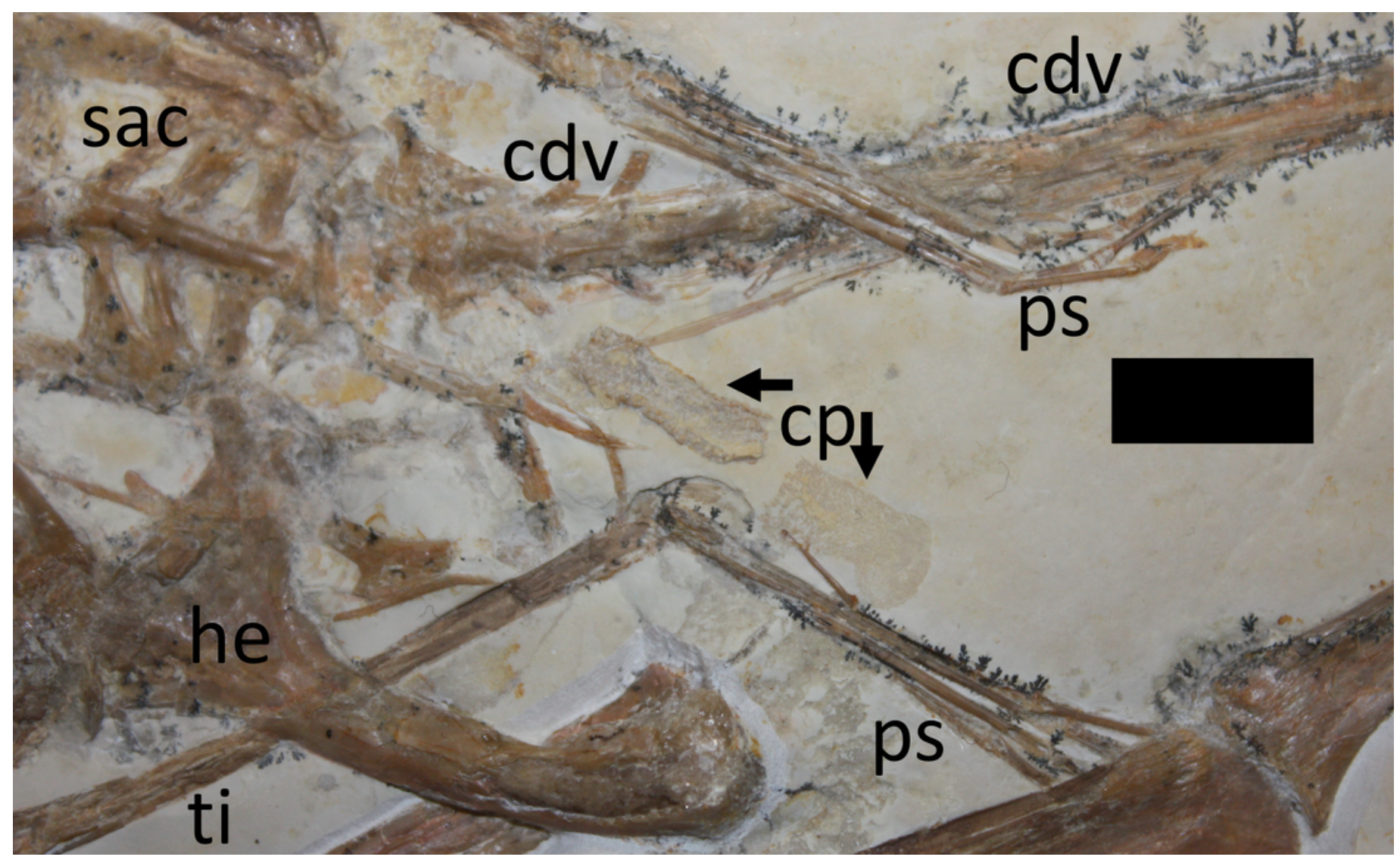




\section{5}

Figure 5

A: Close-up of the left wing showing preserved membranes. B: The wing membranes and tail vane are outlined in pale grey and the coprolites are in dark grey. Abbreviations as above with the following additions: mp, manual phalanges of digits I-IV; ul, ulna, 1-4, wing phalanges 1-4. Scale bar is $100 \mathrm{~mm}$.
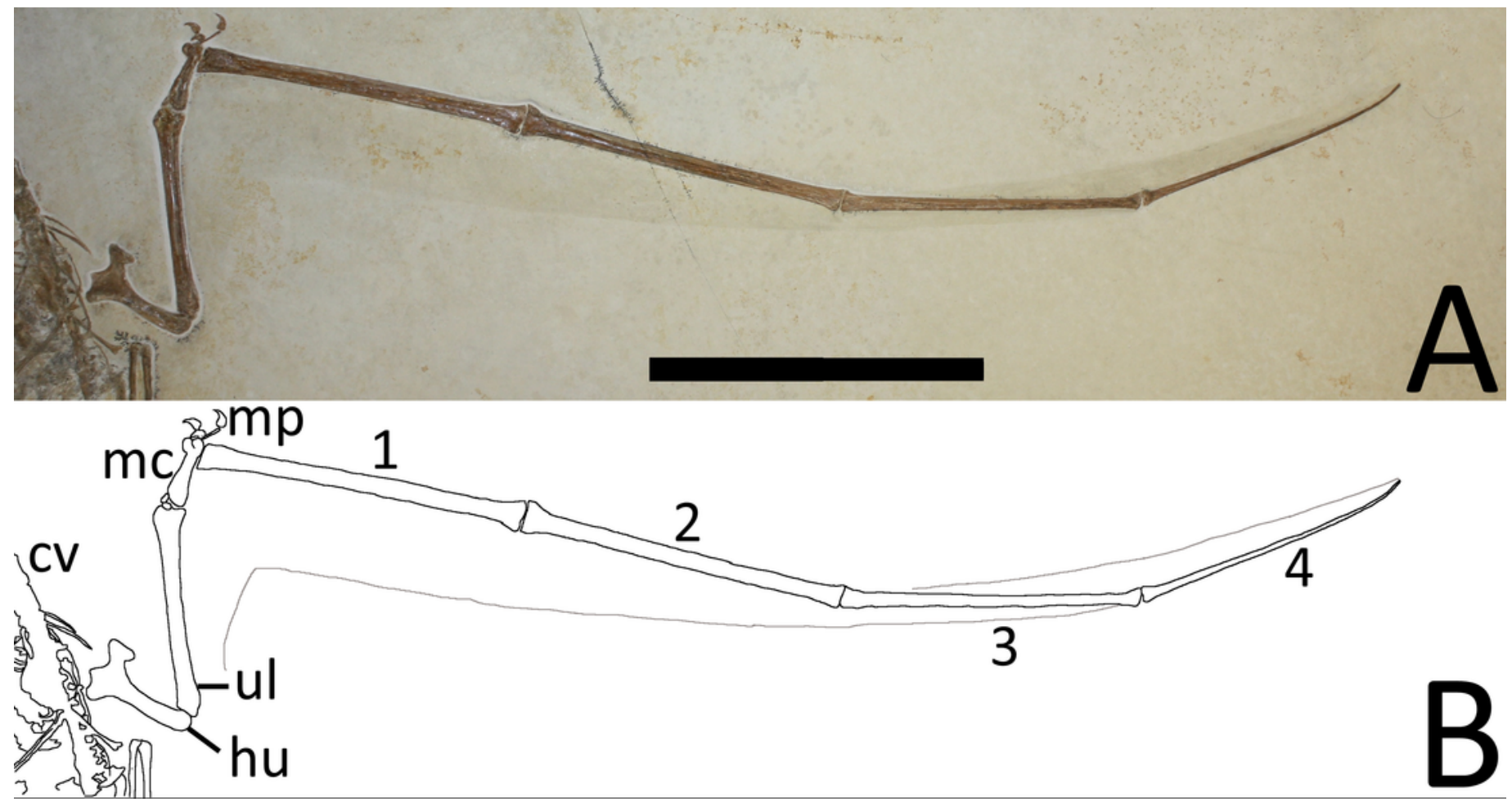


\section{6}

Figure 6

A: Close-up of the right wing showing preserved membranes. B: The wing membranes and tail vane are outlined in pale grey and the coprolites are in dark grey. Abbreviations as above with the following additions: $\mathrm{mp}$, manual phalanges of digits I-IV; ul, ulna, 1-4, wing phalanges 1-4. Scale bar is $100 \mathrm{~mm}$.

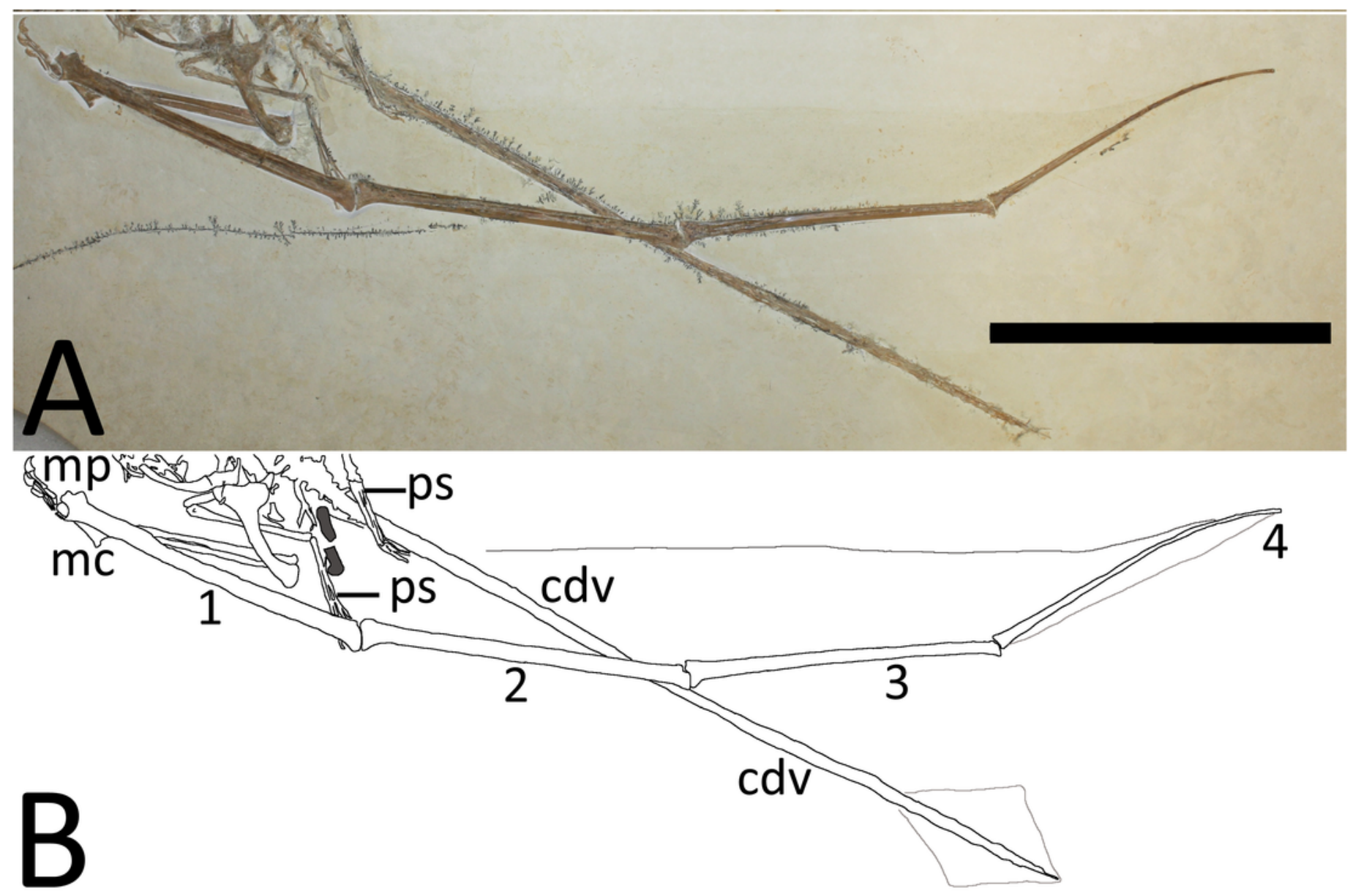




\section{7}

\section{Figure 7}

Figure 7. Photograph taken under binocular microscope of fibrils in the uropatagium. The large element on the right is the right tibia. Scale bar is $1 \mathrm{~mm}$.

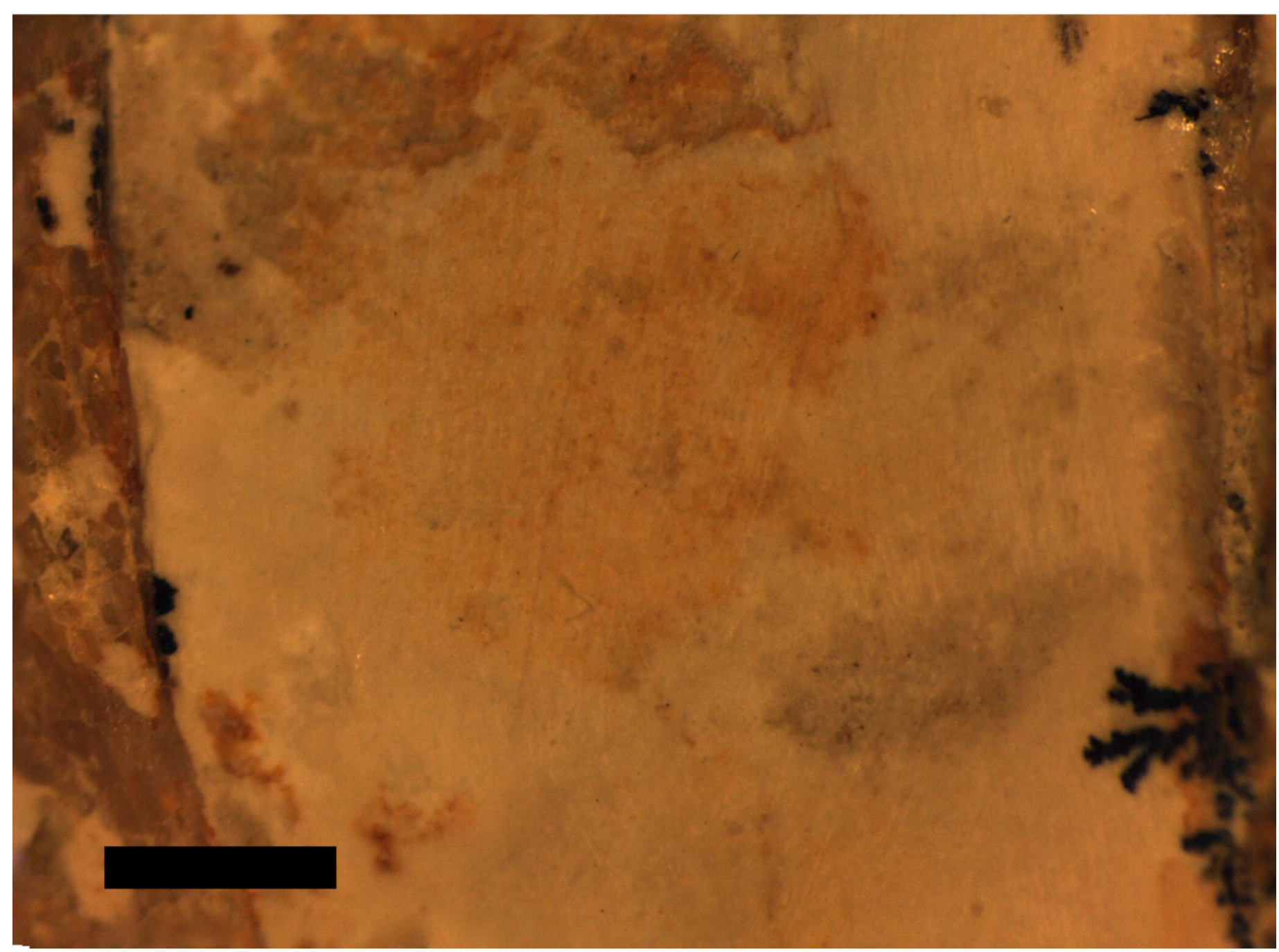




\section{8}

Figure 8

A: Photograph taken under binocular microscope of fibrils in the uropatagium. B: Interpretive drawing of the uropatagium (pale grey) and fibrils (black lines). Not all fibrils are illustrated and the width of the lines may not be representative. Scale bar is $2 \mathrm{~mm}$.
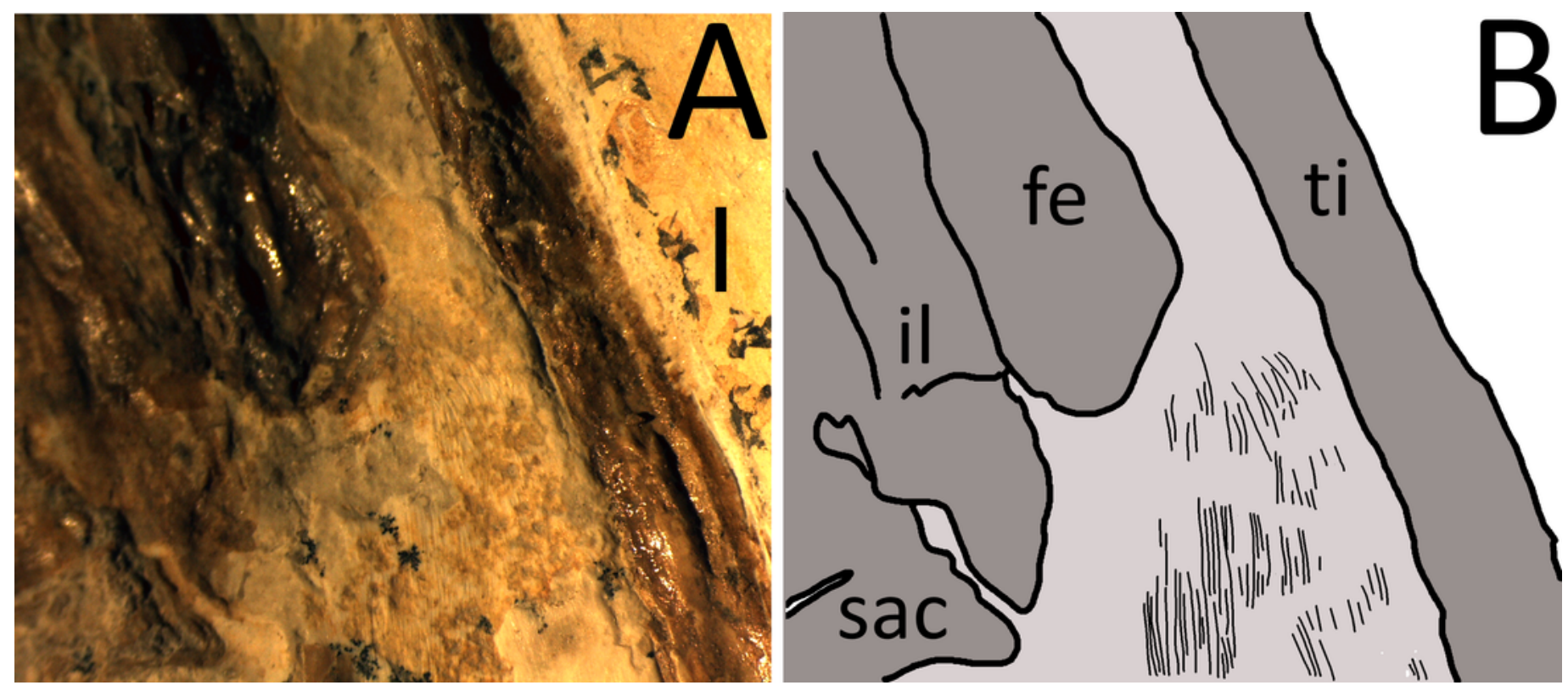
9

Figure 9

Figure 9. Detail of the second part of the coprolite. The series of elements to the left are from the left pes. Scale bar is $5 \mathrm{~mm}$.

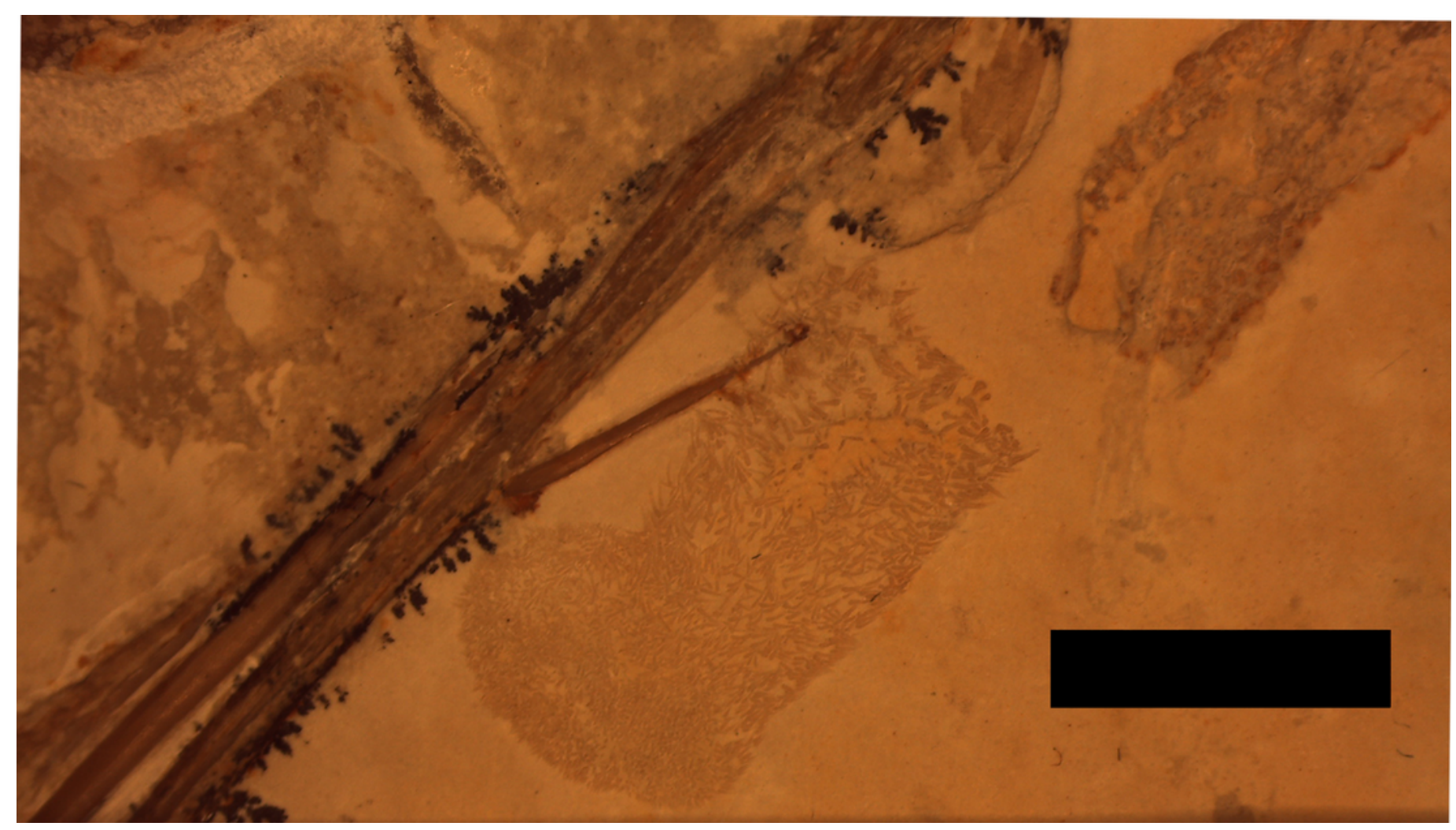




\section{0}

Figure 10

Figure 10. Details of the 'hooklets' within the coprolites. Scale bar is $1 \mathrm{~mm}$.

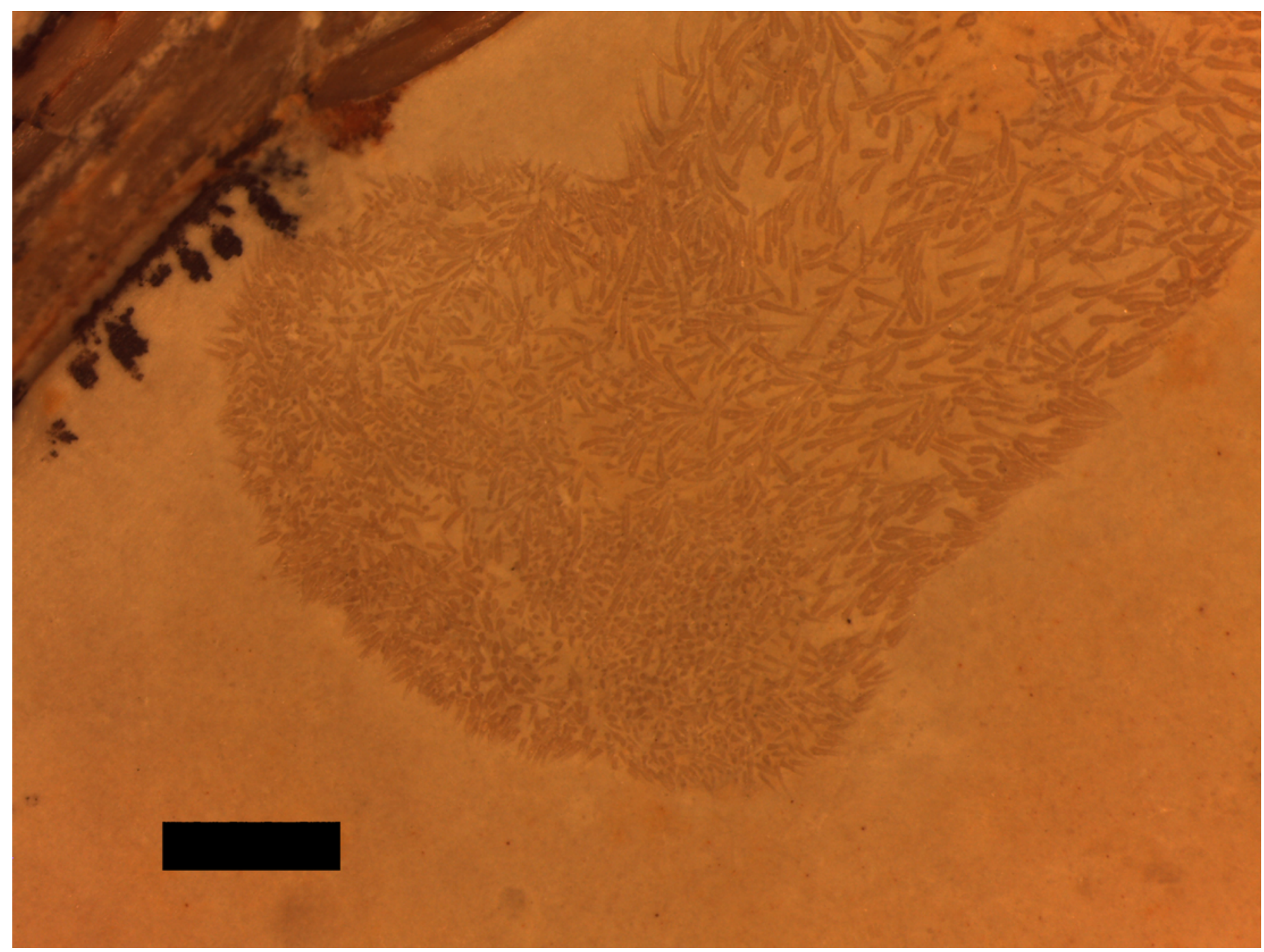




\section{Table $\mathbf{1}$ (on next page)}

Table 1

Measurements of the major elements of TMP 2008.41.001 
1 Table 1: Measurements of the major elements of TMP 2008.41.001.

2

\begin{tabular}{|l|l|}
\hline Element or series & $\begin{array}{l}\text { Maximum length } \\
\text { (to the nearest mm) }\end{array}$ \\
\hline Skull & 91 \\
\hline Cervical vertebrae & 53 \\
\hline Dorsal vertebrae & 52 \\
\hline Sacrum & 13 \\
\hline Caudal vertebrae & 259 \\
\hline Humerus & 33 \\
\hline Radius & 62 \\
\hline Wing metacarpal & 19 \\
\hline Wing phalanx 1 & 96 \\
\hline Wing phalanx 2 & 98 \\
\hline Wing phalanx 3 & 93 \\
\hline Wing phalanx 4 & 94 \\
\hline Femur & 26 \\
\hline Tibia & 38 \\
\hline
\end{tabular}

3

4 